\title{
EPISTÉME E GNÔSIS, CIÊNCIA E SABEDORIA: ACERCA DA DISTINÇÃO ENTRE CONHECIMENTO E COMPREENSÃO NO PENSAMENTO DE JUVENTUDE DE NIETZSCHE ${ }^{1}$
}

Gustavo Bezerra do Nascimento Costa $(\mathrm{UERJ})^{2}$

arqgustavocosta@hotmail.com

Resumo: A partir de uma leitura da crítica perpetrada pelo jovem Nietzsche à vontade de conhecimento que perpassa a modernidade - particularmente com relação às distinções por ele operadas entre: a) duas posturas diante da realidade: o otimismo teórico e pessimismo trágico; b) dois tipos de homem: o teórico e o artista; e c) duas espécies de filosofia e filósofos: do conhecimento desesperado e do conhecimento trágico - procuraremos defender, como chave de leitura para o período de O Nascimento da tragédia, a presença de uma distinção gnosiológica de alcance mais amplo, entre duas formas de acesso ao real: via

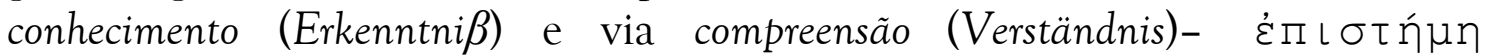
(epistéme) e $\gamma \nu \tilde{\omega} \sigma \mathrm{ls}$ (gnôsis) -, conduzindo respectivamente aos alvos da ciência e da sabedoria.

Palavras-chave: ciência; compreensão; conhecimento; sabedoria.

É possível identificar, de acordo com o próprio Nietzsche em Ecce homo, três intenções ou objetivos principais em $\mathrm{O}$ Nascimento da Tragédia: primeiramente, uma psicologia da

\footnotetext{
${ }^{1}$ Recebido: 08-08-2011/Aprovado em 14-12-2011/Publicado on-line: 30-12-2011.

${ }^{2}$ Gustavo Bezerra do Nascimento Costa é Doutorando em Filosofia pelo programa de pósgraduação da Universidade do Estado do Rio de Janeiro, Rio de Janeiro, Brasil.
} 
tragédia $(2004 \mathrm{a}, 63)^{3}$ : uma interpretação da arte trágica em sua origem, composição e finalidade - a partir da introvisão (Anschauung) dos impulsos que perpassam os estados fisiológico-artísticos na natureza e no homem, aqui personificados em Apolo e Dioniso: as duas divindades protetoras da arte. Tal é o mote para aquilo que irá denominar sua metafísica de artista. Uma segunda intenção ou objetivo seria uma compreensão do socratismo (2004a, 62): uma crítica e denúncia do declínio dessa mesma arte trágica, tendo Sócrates como instrumento de decomposição, pela inserção da racionalidade e do conceito na arte e no pensamento grego. Tal declínio marcaria, para Nietzsche, o fim do homem trágico, o advento da serenojovialidade 4 (Heiterkeit) alexandrina, e posteriormente, do homem teórico moderno. Ambas preparariam caminho para um terceiro e principal intento, embora posteriormente abandonado: a tentativa de, em oposição àquilo que compreendia como a Civilisation francesa - moldada na simples erudição e em uma "cultura geral" (allgemeinen Bildung) sem qualquer "unidade de estilo" (Einheit des Stils) $(1987 b, 6)$-pensar e forjar para o povo alemão uma genuína Cultur" ${ }^{5}$ bem entendida, um "domínio

\footnotetext{
${ }^{3}$ As citações sem referência ao autor referem-se às obras de Nietzsche. A referência completa, desta como das demais citações, encontra-se na bibliografia ao final do texto.

${ }^{4}$ Termo cunhado por Jacó Guinsburg para a tradução brasileira de O Nascimento da Tragédia aqui utilizada.

${ }^{5}$ Não pretendemos aqui enveredar pelo problema da Cultura no pensamento nietzscheano. No entanto, é preciso salientar que Cultur, Kultur e Civilisation, conceitos fundamentais na compreensão do pensamento nietzscheano, particularmente o do jovem Nietzsche, foram empregados em uma diversidade de contextos que, dependendo da tradução, podem suscitar várias interpretações. Particularmente com relação à distinção entre Cultur e Kultur, embora a partir da década de 80 Nietzsche opte pela grafia com "K", em vários fragmentos entre 1872 e 1875 os termos aparecem juntos - algumas vezes até em um mesmo fragmento - ambos traduzidos para o português, ora como "civilização", ora como "cultura"; o que, de todo modo, faz crer que não se trate de uma mera opção estilística do filósofo. Poderíamos àqueles termos ainda acrescentar Bildung (em alemão: formação, instrução, cultura), que é traduzido ora como "cultura", ora como "formação", mais próxima do sentido da paidéia grega. Tal é o motivo, de resto, da opção pela grafia de tais Cont.
} 
unificante dos instintos" (NIETZSCHE KSA, VII, 19[41] 1872-3, 432) de um povo, ou ainda, uma "unidade de estilo artística" em suas próprias manifestações (2003b, 35) - com o vislumbre de um renascer da arte e cultura trágicas da Grécia arcaica, através da filosofia de Schopenhauer e do gênio artístico-musical de Wagner.

Ora, se a possibilidade de tal renascimento no seio do povo alemão é, pouco tempo depois, rechaçada por Nietzsche - o desencanto com Wagner, particularmente, levara-o a isto - o mesmo não se pode dizer das contundentes críticas à moderna Civilisation, corolário da inartística cultura socrático-alexandrina. Os momentos acima de nascimento, morte e suposto renascimento da Cultur grega moldada pela tragédia são aqui a face visível, digamos, da ferrenha crítica nietzscheana à modernidade em seus pilares: racionalidade, ciência e moral, bem como à sua arte e gosto decadentes em particular, como veremos, à vontade de conhecimento que a norteia. Tal crítica, que no pensamento de juventude de Nietzsche gira em torno do conceito de pessimismo, sob matizes e perspectivas distintas percorrerá o seu pensamento até a maturidade, culminando com a noção de niilismo ${ }^{6}-$ estado psicofisiológico de decadência desvalorização dos valores, decorrência de um voltar-se contra si da moral cristã, impulsionada pela vontade de veracidade que nasce em seu seio e que, com a ciência, atinge o seu cimo.

Apoiando-nos então nas duas grandes "novidades" de O Nascimento da tragédia: psicologia da tragédia e compreensão

\footnotetext{
termos em alemão.

${ }^{6}$ Também para o Nietzsche da maturidade a "vontade de verdade" vem a ser, do ponto de vista gnosiológico, o grande propulsor do niilismo na modernidade pela interdição, como ilusão e falsidade, da construção de sentido perpetrada pela moral. Moral no seio da qual aquela mesma vontade de verdade surgiu. Cf. NIETZSCHE (KSA, XII, 5[71] 1887, 211-5). Cf também, a esse respeito, o artigo de O. Giacóia (2007); e ainda o texto de Araldi(2004).
} 
do socratismo, procuraremos primeiramente abordar um dos aspectos da crítica do jovem Nietzsche à modernidade - a vontade de conhecimento que a norteia - à luz das oposições por ele operadas entre: duas posturas diante da realidade e dois tipos de homem. Com este enfoque, buscamos compreender uma terceira diferenciação, agora entre duas espécies de filosofia e filósofos: do conhecimentotrágico (tragischen Erkenntni $\beta$ ) e do conhecimentodesesperado (desperaten Erkenntni $\beta$ ). Como procuraremos defender, esta aponta para a presença, em seu pensamento de juventude pelo menos, de uma distinção gnosiológica mais ampla, entre duas formas de acesso ao real: via conhecimento e via compreensão, conduzindo, respectivamente, à ciência e à sabedoria.

A imitação, no pensamento do jovem Nietzsche, é "o meio para toda cultura" [Kultur], pelo qual "o instinto pouco a pouco se forma” (NIETZSCHE 1872-3, KSA-VII, 19[226], 489). E os gregos - a "mais bela [e] mais invejada espécie de gente até agora" (2003a, 13-4) - pelo ideal de cultura que suscitam, são sua referência. Uma anotação um pouco posterior, de 1875 , não parece deixar dúvidas: "Eu quero obter a soma de Schopenhauer, de Wagner e da Grécia arcaica: isso abre uma perspectiva de cultura magnífica" (NIETZSCHE 1875, KSA-VIII, 6[14], 103). Esta referência, no entanto, não se dá pela "mesma via" com a qual alguns pensadores, a partir de Winckelmann, Schiller e Goethe, aspiraram unir as culturas helênica e alemã (2003a, 120). Emerge de uma reinterpretação daquilo que o filósofo define como "o sério e importante conceito da 'serenojovialidade grega'" (2003a, 63-4), a Heiterkeit, que para ele não pode ser compreendida como mero "bem-estar não ameaçado" (2003a, 63-4), mas como signo de cansaço e declínio, decorrência de um lento e prolongado olhar no 
que há mais terrível na existência, que, sem a arte como espelho transfigurador, conduz a "um senil e improdutivo prazer na existência”, "oposto da esplêndida 'ingenuidade' dos helenos antigos" (2003a, 107).

Como fica particularmente claro na Tentativa de autocritica incorporada pelo autor em 1886 à segunda edição de sua obra de estreia - e que de resto justifica também a alteração do subtítulo para Helenismo e pessimismo -, é então, por meio de uma suspeita acerca da Heiterkeit que Nietzsche irá construir sua própria "via de acesso" à cultura grega.Tal suspeita - que também nos remete à forma de interpretação genealógica que irá desenvolver na maturidade - torna-se possível pela atenção a duas características peculiares ao grego: uma exacerbada disposição para o sofrimento e uma extrema sensibilidade para a arte. O Nascimento da Tragédia seria assim a tentativa de chegar a uma resposta para duas questões fundamentais: Qual a relação, nos gregos, entre arte e pessimismo? O que isso significa para uma cultura? Tais questões comporão, a partir daqui, o fio-condutor de nossa investigação.

Em sua metafísica de artista, como mencionamos acima, Nietzsche concebe os estados apolineo e dionisíaco, primeiramente como apresentações metafísicas do mundo, respectivamente como Representação e como Vontade ou para sermos agora mais precisos ${ }^{7}$, utilizando os termos ado-

\footnotetext{
${ }^{7}$ Foge aos nossos propósitos adentrarmos aqui a questão acerca da pertinência ou não com que é feita a correlação da introvisão nietzscheana com o pensamento de Schopenhauer. Gostaríamos apenas de indicar que a mera equiparação conceitual entre a Vontade schopenhaueriana e o UrEine de Nietzsche - e de modo geral uma mera aceitação da filosofia de Schopenhauer pelo jovem Nietzsche, como veremos a seguir - está longe de ser ponto passivo. Conferir a este respeito, por exemplo, (NIETZSCHE2007, 167-181).Cf. também: Cavalcanti (2004, 1-16): "Neste fragmento, Nietzsche não apenas deixa clara, em uma atitude bastante diferente daquela adotada em GT [O Nascimento da tragédia], a diferença de sua reflexão em relação a de Schopenhauer, como explicita o distanciamento do conceito central desenvolvido em sua primeira obra, o de Uno Primordial, Cont.
} 
tados por Nietzsche - como ilusão submetida ao Véu de Maya e como Uno-primordial (Ur-Eine). Em uma segunda acepção, agora no homem, o apolíneo e o dionisíaco manifestam-se como estados fisiológicos: do sonho configurador e da embriaguez pulsional. Já em uma terceira acepção tais estados são, pela sensibilidade artística do grego, convertidos em duas formas distintas, mas aparentadas, de manifestação artística: de um lado a arte apolínea, da ordem e da medida, expressa nas "belas formas" das artes plásticas e na "reluzente" e "ingênua" poesia épica. De outro, a arte dionisíaca, inebriante, delirante e desmesurada, expressa na música extática do coro de sátiros das orgias báquicas. Dizemos "aparentadas" porque o fenômeno artístico, em sua forma configuradora - em sua apresentação - é sempre apolíneo. Se por um lado a arte apolínea não é uma afirmação, digamos, integral, mas muito mais uma visão ingênua da vida já que é "aparência da aparência" (2003a, 40)- por outro lado, tampouco é possível afirmar a força artística dionisíaca como subsistente por si, sem o elemento apolíneo de configuração. Dioniso mesmo, fonte de criação e destruição, só se mostra, enquanto arte, através de Apolo ${ }^{8}$.

em relação à metafísica da vontade. Diferentemente desta concepção, na qual a libertação do sofrimento só é possível a partir da negação da vontade, como resignação passiva, a concepção de Nietzsche é caracterizada pela libertação do sofrimento em uma ativa e prazerosa criação da aparência. A vontade, compreendida por Schopenhauer como vontade metafísica, passa a ser compreendida como a forma mais universal da aparência, como um momento do processo de objetivação do Uno Primordial" (p.2).

${ }^{8}$ (cf. NIETZSCHE 2003a, §6, 50). A música dionisíaca, por exemplo, "aparece como vontade", embora seja "impossível que a música, segundo a sua essência, seja vontade, já que ela, como tal, deveria ser completamente banida do domínio da arte - porquanto a vontade é em si o inestético; porém aparece como vontade". (cf. NIETZSCHE 2005, 31): "Assim como na vida apolínea penetrou o elemento dionisíaco, assim como a aparência também aqui se estabeleceu como limite, a arte dionisíaco-trágica não é mais 'verdade'. Aquele cantar e dançar não é mais a instintiva embriaguez da natureza [...]. A verdade é agora simbolizada, ela serve de aparência, ela pode e precisa por isso também usar as artes da aparência. [...] Quem vence o poder da aparência e a despotencializa até o símbolo? Trata-se da música". 
A arte trágica tem sua origem e magnitude precisamente no confronto entre esses dois estados e na transfiguração (Verklärung) que impõem um ao outro: Apolo domesticando, pela forma configuradora, a Dioniso; Dioniso subjugando, pelo conteúdo desfigurador, a Apolo. Ator e cena representando a música dionisíaca; o coro animando ator e cena - o trágico, pela tragédia, deixa de sê-lo, convertendo-se em afirmatividade.

Tal equilíbrio de forças, porém, dura pouco. Pelas mãos de Sófocles, mas principalmente com Eurípides, o confronto e a transfiguração logo revelam, na arte trágica, o predomínio dos elementos apolíneos - ator, cena e palavra - sobre a música dionisíaca. Como parece claro em A Visão dionisiaca do mundo - conferência preparatória a O Nascimento da tragédia - com a transposição de imagens em metáforas, as linguagens tonal (Tonsprache)e gestual (Geberdensprache) do coro dos ditirambos perdem força frente à linguagem conceitual (Wortsprache) (2005, 32-40) ${ }^{9}$. Em nome de sua "compreensão" e "popularização" - com a introdução da linguagem conceitual e sua conseqüente "racionalização" - o trágico já não é mais domesticado, mas suprimido: "Excisar da tragédia aquele elemento dionisíaco originário [...] e voltar a construí-la de novo puramente sobre uma arte, uma moral e uma visão do mundo nãodionisíacas" (2003a, 78). Tal é a tendência de Eurípides que, no entanto, não fala por si, mas por um "demônio de recentíssimo nascimento" chamado Sócrates - esse, o grande artífice da degenerescência perpassa todo o ocidente e

\footnotetext{
9 (NIETZSCHEKSA,VII:3[15][16][18], 1869-70, 63-5). Cf. também a esse respeito: (CAVALCANTI 2004). A referida tese foi publicada em livro com o mesmo título em 2005, pela editora Anna Blumme.
} 
alcança a modernidade européia: da tragédia em drama épico, da Cultur grega em uma "débil" Civilisation e do homem trágico-artístico em homem teórico. Todas as transformações por que passa a tragédia teriam, então, um fundo comum: de Sófocles a Eurípides, de Eurípides a Sócrates, o fim da arte trágica marcaria o advento do espírito racionalcientífico e o engendramento da cultura socráticoalexandrina, com seu posterior desdobramento na "civilização"moderna.

Chegando a esse ponto, podemos direcionar nossa investigação para a problematização que a motiva.

$\mathrm{Na}$ arte trágica, o contato com o Uno-primordial, com a sabedoria dionisíaca - "aquele que por seu saber precipita a natureza no abismo da destruição há de experimentar também em si próprio a desintegração da natureza" (2003a, 65) - tal contato conduz o herói trágico a seu inevitável aniquilamento. No entanto, o pessimismo e o horror da existência daí decorrentes são, pela suprema arte, convertidos em suprema afirmatividade. Só com a mediação da arte pode o contato com Uno-primordial não se transformar em náusea e repulsa diante da vida. Só como "fenômeno estético" (2003a, 47/141) podem a existência e o mundo serem justificados. A arte tem então uma significação metafísica ilusória, mas necessária - de constituição de valores diante da vida: "A arte como a tarefa própria da vida, a arte como sua atividade metafísica" (NIETZSCHE 1887-8, KSAXIII:11[415], 193-4; 1987a, 27-8). Nos gregos, ela é o tônico que, mascarando - arte apolínea - ou sublimando - arte trágica - o horror da existência, converte o pessimismo em afirmatividade. Particularmente com relação à arte trágica, é por meio dela que, para Nietzsche, torna-se possível a formação de uma cultura (Cultur) genuína, radicada em uma 
afirmação trágica da existência e tipificada no homem trágico-artístico.

De fato, em seu pensamento de juventude, é por meio de uma "ilusão distendida sobre as coisas" - de "estimulantes" pelos quais as "naturezas mais nobremente dotadas, que sentem [...] o fardo e o peso da existência", são "enganadas por si mesmas" - que a Vontade (Wille) prende à vida as suas criaturas e as obriga a prosseguir vivendo (2003a, 108). Seja como pretensão de curar pelo conhecimento a "ferida eterna da existência", seja como o "véu" transfigurador da beleza artística, seja ainda como consolo metafísico de uma vida eterna "sob o turbilhão dos fenômenos", o engano de si,próprio à vontade de ilusão é aqui o que impulsiona e dá sentido à vida (2003a, 108). De acordo com o grau e mescla das formas dessa ilusão-estimulante compõe-se, segundo Nietzsche, tudo o que até então pode ser compreendido sob o nome de cultura, seja ela: socrática (alexandrina), artística (helênica) ou trágica (budista).

Partindo desta gradação, parece-nos possível compreender, agora em um cenário oposto ao do florescimento da arte trágica, o cerne da crítica do jovem Nietzsche a Sócrates e àquilo que representa: a vontade de conhecimento a qualquer custo. Poderíamos aqui perguntar: dado que as duas, ou mesmo as três formas de cultura acima apresentadas são perpassadas por uma ilusão estimulante, o que leva então Nietzsche a fazer apologia a uma cultura artística, ou trágico-artística, em detrimento de outra, socrático-alexandrina? Uma resposta rápida, e até certo ponto rude, nos conduziria a uma anotação de 1875, na qual afirma: "Eu não procuro na história as épocas felizes, mas aquelas que proporcionam terreno favorável à produção do gênio" (NIETZSCHE 1887-8, KSA-VIII, 6[43] 1875, 114). Mas o 
que isso significa?

Como afirma em sua já citada Tentativa de autocritica, a ciência é então pela primeira vez compreendida como problemática, mas tal problema não poderia ser reconhecido no terreno próprio da ciência. É preciso avaliar "a ciência com a óptica do artista, mas a arte, com a óptica da vida” (2003a, 15). Com o fim da tragédia perpetrado por Sócrates (2003a, 79), a relação entre arte e pessimismo - relação essa que culmina com uma afirmação trágica da existência - é substituída por outra, entre ciência e otimismo. $\mathrm{O}$ pessimismo prático, o horror ao trágico e à existência de um modo geral $(2003 a, 56)$ já não é mais domesticado esteticamente pela tragédia - nem mesmo pela descarga artística do cômico - e, dessa forma, transformado em afirmatividade. Antes, é convertido em estratégias de controle e manipulação da realidade por meio do conhecimento, configurando assim o otimismo teórico que marca a cultura socráticoalexandrina. Seu "ideal" de homem (2003a, 108) não é mais o artista apolíneo-dionisíaco, afirmador da sabedoria trágica, mas o teórico par excellence: o cientista que, na ânsia em abarcar o real em sua totalidade e suas profundezas (2003a, 94), tudo controla e tudo conhece, porém, nada cria e nada significa. Ao contrário do artista trágico, importa ao homem teórico não o que está por desvelar, mas o próprio desvelar, o véu desprendido. E nessa redução da vida à estrutura lógico-racional da faculdade cognitiva, tudo o que a ela escapa é falso - ou um contra-senso. O que o impulsiona, aparentemente, não é mais uma vontade de ilusão e encanto, mas antes, uma vontade de conhecimento: não o compreender, ou ainda, o saber, está aqui em jogo, mas tão somente conhecer - para além, como veremos, do mero jogo de palavras. Importa-lhe, como pensamos, o conhecimento (Erkenntni $\beta$ ) 
e não a compreensão (Verständnis) que conduziria à sabedoria (Weisheit) própria de uma cultura trágica.

Ora, em Nietzsche - em particular, no período de $\mathrm{O}$ Nascimento da tragédia - a recusa às pretensões do saber racional-científico, e em um sentido mais amplo à cultura que aí se engendra deve-se, em primeiro lugar, à forma peculiar de ilusão aí presente. Como vimos acima, é só como engano de si mesmo que a "ferida da existência" é curada pelo conhecimento, tanto quanto é justificada pela arte. No entanto, ao contrário desta, no conhecimento teórico a "ilusão distendida sobre as coisas" adquire a forma de um peculiar autoengano: uma ilusão de não depender de ilusões, ou, em outras palavras, uma vontade de desilusão. Aqui, o "aguilhão" da sabedoria trágica se mostra e vem à tona o contra-senso que se esconde sob o otimismo teórico, precipitando não só a natureza, mas o conhecedor mesmo, no "abismo da destruição" (2003a, 65): na ânsia sempre frustrada e sempre renovada, de "abarcar, em círculos cada vez mais largos, o mundo inteiro dos fenômenos" (2003a, 95), a lógica inerente à ciência passa a girar ao redor de si própria - ponto no qual a vontade de desilusão compreende-se como ilusãoestimulante.

É bem verdade que também a arte mostra-se a Nietzsche como uma forma de autoengano: uma "ilusão distendida sobre as coisas" que, com o véu da beleza, impele a continuar vivendo. No entanto, como explicita em um fragmento um pouco posterior a O Nascimento da tragédia: "Como é possível a arte enquanto mentira? [...] A arte detém a alegria de nos despertar das crenças por meio das superfícies: mas não somos enganados! Pois então a arte cessaria. [...] A arte acolhe, pois a aparência enquanto aparência, então não quer enganar, é verdadeira" (NIETZSCHE 
1887-8, KSA-VII: 29[17], 1873, 632-3). A ilusão, nesse sentido, não se pretende desilusão.

Aqui, a oposição entre duas posturas diante da realidade: o otimismo teórico, conduzido pelo conhecimento, e o pessimismo trágico, domesticado pela arte; assim como uma segunda, entre os dois ideais de homem que as tipificam: o teórico e o artista conduzem-nos a uma terceira diferenciação: entre duas concepções de filosofia e filósofos. Para o jovem Nietzsche, explicitado o autoengano presente nas pretensões do otimismo teórico, o conhecimento reconhece seus limites e rende então à arte o papel de conferir sentido à existência. Momento em que vem à tona a distinção entre uma filosofia do conhecimento desesperado (desperaten Erkenntni $\beta$ ) e outra, do conhecimento trágico (tragischen Erkenntni $\beta$ ). Enquanto aquela tem pretensões de fundamentação e é conduzida por uma ciência cega: "o saber a qualquer custo", a outra "domina o instinto de conhecimento [...] [e] restabelece os direitos da arte" (NIETZSCHE 1887-8, KSA-VII: 19[35], 1872-3, 427-8), assumindo o papel de avaliadora e legisladora do conhecimento perante a vida. Para o filósofo, a modernidade e sua "cultura geral" teria sua filosofia como mero "monólogo erudito do passeador solitário", voltada apenas à "aparência erudita". Seria preciso ter antes uma Kultur, para se saber "o que a filosofia quer e pode" (1987b, 6-7). Kant e Schopenhauer, segundo ele, foram até então aqueles que "souberam utilizar com incrível sensatez o instrumento próprio da ciência, a fim de expor os limites e condicionamentos do conhecer em geral e, com isso, negar definitivamente a pretensão da ciência à validade universal e metas universais" (2003a, 110-1). Filósofos do conhecimento trágico conquistaram com isso, "a vitória sobre o otimismo oculto na essência da lógica" (2003a, 110-1), que 
é, por sua vez, base do socratismo teórico e substrato de nossa Civilisation.

É então, primeiramente, o peculiar autoengano presente nas pretensões do otimismo teórico o que leva Nietzsche a recusá-lo em seus propósitos edificantes. Mas há ainda um segundo e importante aspecto de tal recusa, pelo qual esperamos chegar ao cerne de nossa investigação - qual seja o pressuposto, no pensamento de juventude de Nietzsche, de uma distinção gnosiológica entre conhecimento (Erkenntni $\beta$ ) e compreensão (Verständnis).

De fato, a vontade de desilusão presente no conhecimento racional oculta, segundo Nietzsche, uma motivação mais ambiciosa, embora também mais perniciosa.Com a equiparação: "Razão = Virtude = Felicidade", o otimismo teórico anseia não mais justificar, mas sim conhecer e corrigir a existência, destruindo o encantamento pelo qual esta adquire sentido: "aquela inabalável fé de que o pensar, pelo fio condutor da causalidade, atinge até os abismos mais profundos do ser e que o pensar está em condições não só de conhecê-lo, mas inclusive de corrigi-lo" (2003a, 93) - e ao corrigi-lo, curá-lo. Por trás dessa correção da existência pelo conhecimento revela-se, assim, uma condenação ética:"Virtude é saber; só se peca por ignorância; o virtuoso é o mais feliz"(2003a, 89), tal é o ensinamento de Sócrates. Tal qual a virtude em relação ao vício, o conhecer é preferível ao intuir, ou ainda ao desconhecer.

Tal condenação, no entanto - também antecipando o genealogista da maturidade - ocultaria ainda um temor fisiológico: ante o imprevisível e o instintivo. $\mathrm{O}$ otimismo teórico aqui expressa o seguinte: a existência é por si temivel, portanto, eticamente condenável; no entanto, é cognoscivel, logo, corrigível.

“Apenas por instinto": por essa expressão tocamos no ponto central 
da tendência socrática. Com ela, o socratismo condena tanto a arte quanto a ética vigente; para onde quer que dirija seu olhar perscrutador, avista ele a falta de conhecimento (Einsicht) e o poder da ilusão; dessa falta, infere a íntima insensatez e a detestabilidade do existente. A partir desse único ponto julgou Sócrates que deveria corrigir a existência... (2003a, 85, com pequena alteração na tradução).

Ora, dirá Nietzsche, "É preciso querer até a ilusão - nisto consiste o trágico" (2003a, 85, com pequena alteração na tradução). Remetendo ao ensinamento de Hamlet - o que também poderia ser estendido ao "homem subterrâneo" de Dostoievski - "o conhecimento mata a atuação, para atuar é preciso estar velado pela ilusão" (2003a, 56). Longe de fazer frente à temerária sabedoria trágico-artística, a pretensão própria ao conhecimento científico-otimista, de controlar e corrigir a realidade - seu caráter não-mítico, não-intuitivo e nãocriativo - revela antes "um temor e uma escapatória ante o pessimismo" (2003a, 14), ante o intangível e o incognoscível - enfim, ante o trágico.

Se, portanto, o otimismo teórico é refutado por Nietzsche, isto se dá não somente pela forma de autoengano na qual envereda - ilusão da desilusão - mas também, e principalmente, porque aqui é a vida mesma que, por temor, é condenada. Embora otimista, e talvez por isso mesmo, não é afirmativo. $O$ conhecimento que o impulsiona não conduz a uma sabedoria - senão enquanto conhecimento trágico, que compreende e expõe seus próprios limites, voltando-se para uma crítica do saber. É só com tal radicalização, como vimos na forma de uma filosofia do conhecimento trágico perpetrada por Kant, Schopenhauer e ele próprio, que $\mathrm{Ni}$ etzsche vê na modernidade um "terreno favorável à produção do gênio", prenhe de sabedoria trágica, e o alvorecer de uma nova Cultur. 
Como defendemos, parece ser possivel remeter a diferenciação entre estas duas formas de conhecimento: desesperado e trágico, a uma esfera de alcance mais amplo,

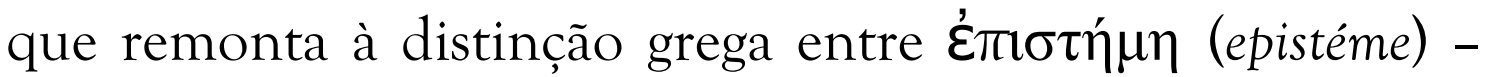
enquanto conhecimento intelectual, aplicado, oposto à $\delta o ́ \xi \alpha($ dóxa, opinião) - e $\gamma v \tilde{\omega} \sigma ı \varsigma$ (gnôsis) - enquanto conhecimento superior, intuitivo, criador de sentido, oposto à

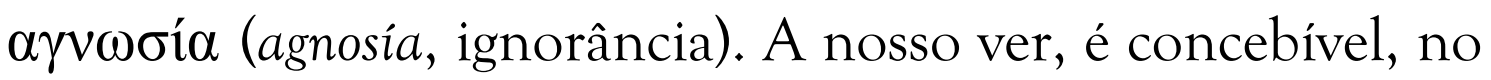
pensamento do jovem Nietzsche pelo menos, a retomada de uma distinção reconhecível também na filosofia de Schopenhauer ${ }^{10}$, entre conhecimento (Erkenntni $\beta$ ) e compreensão (Verständnis).

Podemos encontrá-la já na leitura crítica que, em 1868, o jovem Nietzsche faz do pensamento de seu educador, nas anotações reunidas sob o título Fragmente einer Kritik der schopenhauerischen Philosophie ${ }^{11}$, no primeiro volume das obras completas de Nietzsche publicadas em 1922 pela editora Musarion. Na leitura que aqui faz - em boa parte influenciado por F. A. Lange ${ }^{12}$ e sua revisão em bases fisiológicas do programa kantiano -, se por um lado o

\footnotetext{
${ }^{10}$ Remetemos aqui à excelente tese de doutorado intitulada: Schopenhauer: uma filosofia do limite, recentemente defendida por Ruy de Carvalho R. Jr. na Pontifícia Universidade Católica de São Paulo, em 15 de junho de 2011. Tese que tem como fio-condutor a defesa de uma articulação, no pensamento de Schopenhauer, entre "aquilo que se pode conhecer e aquilo que se pode compreender", interpretando a concepção schopenhaueriana do mundo como Vontade como uma espécie de "hermenêutica da Representação", ou ainda, uma "hermenêutica da experiência". Para o autor, em Schopenhauer, a "recusa ao conhecimento do interior dos fenômenos do mundo" não implica uma renúncia acerca de sua significação. Em outras palavras, "o veto a toda pretensão de conhecimento da essência do mundo não conduz à renúncia ao pensamento do sentido imanente a todas as coisas" (cf. RODRIGUES 2011, 305f. 15-6).

${ }^{11}$ (cf. NIETZSCHE [1922?], 392-401). Tais fragmentos aparecem sob o título Zu Schopenhauer no primeiro volume das obras completas publicadas sob a supervisão de G. Colli e M. Montinari: NIETZSCHE, F.W. Werke.Kritische Gesamtausgabe (KGW, I/4, Herbst 1867- Frühjahr 1868, 57 [51-55], pp. 418-427). Cf. a esse respeito: LOPES, (2008, 127. nota 93).

${ }^{12}$ LANGE, ([195-]). Para Lange, a revisão em bases fisiológicas do programa filosófico kantiano dar-se-ia em paralelo com a ratificação da sua tese acerca da "inevitabilidade antropológica" da metafísica. Cf. a este respeito: LOPES (2008, 23 e 40-84).
} 
pensamento de Schopenhauer é criticável por construir uma metafísica que, embora imanente, fundada na intuição do próprio corpo como vontade, não reconhece o seu o caráter ficcional e poético, permanecendo ainda presa ao dogmatismo ${ }^{13}$ - em outras palavras, se sua metafísica não se sustenta do ponto de vista epistêmico pós-kantiano -, por outro lado, tal crítica seria um aspecto menor diante do "propósito edificante" que seu pensamento nos fornece: não uma explicação (Deutung, Erklärung), mas uma significação (Bedeutung) da essência do mundo.

Todo pensar ético se pronunciaria contra um tal emaranhado de possibilidades. Contudo, precisamente contra esta objeção ética poder-se-ia replicar que o pensador, confrontado com o enigma do mundo, não tem outro recurso senão justamente tentar decifrá-lo. Isto é, na esperança de que um momento genial the coloque nos lábios a palavra que fornece a chave para aquele escrito que está diante de todos os olhos sem ter sido jamais lido, e que nós chamamos mundo (NIETZSCHE, Werke.Kritische Gesamtausgabe. I/4, p. 422. Apud. LOPES 2008, 134.)

Não o conhecimento (Erkenntni $\beta$ ) do mundo, mas a sua compreensão (Verständnis), portanto, é o que aqui está em jogo. É o que também nos sugere a carta escrita, ainda em 1866, a Carl von Gersdorff:

Não apenas a verdadeira essência das coisas, a coisa em si, é desconhecida para nós; também seu conceito é, nada mais nada menos, que o último rebento de um contraste condicionado por nossa or-

\footnotetext{
${ }^{13}$ (cf. LOPES 2008, 29-30). Como afirma Lopes: "Diferentemente de Kant e Lange, Schopenhauer tenta argumentar a favor da existência de um interesse teórico legítimo, ou seja, não apenas de fato, mas também de direito, pelo tipo de questionamento identificado como metafísico no interior da tradição crítica. Schopenhauer concorda que a motivação essencial para a metafísica é de natureza prática ou existencial [grifo nosso], mas seu programa de uma metafísica pós-dogmática, fundada em um tipo especial de experiência, apela também para motivações estritamente teóricas [...].Com exceção de Schopenhauer, os demais adeptos da tese da inevitabilidade antropológica da metafísica são céticos em relação à possibilidade da metafísica enquanto ciência. Mas isso não significa, na perspectiva do idealismo prático, que o impulso metafísico possa ou deva ser eliminado”.
} 
ganização, do qual não sabemos se conserva algum significado fora de nossa experiência. Disso resulta [...] que os filósofos não devem ser importunados na medida em que nos edificam. A arte é livre, também na região dos conceitos. [...] Como você pode perceber, o nosso Schopenhauer resiste mesmo a este mais rigoroso ponto de vista crítico, ele se torna quase ainda mais valioso para nós. [...] se a filosofia deve edificar, então eu pelo menos não conheço nenhum filósofo que edifique mais do que nosso Schopenhauer (NIETZSCHE, KSB-II, pp. 159-160; Apud. LOPES 2008, 86-7).

Não é à toa, nesse sentido, que o jovem Nietzsche reconhece em Schopenhauer, a despeito da aparente inclinação a um dogmatismo pré-kantiano, a expressão de uma filosofia do conhecimento trágico e o renascer de uma cultura trágica. Como vimos, a uma filosofia trágica caberia, tomando a ciência sob a óptica da arte, e esta sob a óptica da vida, reconhecer os limites do conhecimento e mostrar a necessidade da ilusão e da arte para a vida (NIETZSCHE 1872-3, KSA-VII: 19[35], 427-8) por meio de uma compreensão de seu significado. Expressando a "sabedoria dionisíaca em conceitos" (2003a, 110), o filósofo seria então instrumento para formação de uma Cultur.

No horizonte da crítica do jovem Nietzsche à modernidade, como procuramos aqui defender, tal reconhecimento galgado na distinção entre duas formas de filosofia tem, por um lado, seus alicerces na distinção entre duas posturas diante da realidade: o otimismo teórico e o pessimismo trágico-afirmativo, bem como entre dois tipos de homem: o teórico e o artista-trágico; por outro, a pressuposição de um horizonte gnosiológico mais amplo, que diferencie entre conhecimento e compreensão, ou antes, entre conhecimento teórico e compreensão trágica.

Conduzido então pela busca da compreensão do significado da existência, o filósofo trágico já não tem ciência 


\section{como "alvo supremo", mas antes, a sabedoria":}

Com esse conhecimento (Erkenntni $\beta$ ) se introduz uma cultura (Cultur) que me atrevo a chamar trágica: cuja característica mais importante é que, para o lugar da ciência (Wissenschaft) como alvo supremo, empurra-se a sabedoria (Weishei), a qual, não iludida pelos sedutores desvios das ciências, volta-se com olhar fixo para a imagem conjunta do mundo, e com um sentimento simpático de amor procura apreender nela o eterno sofrimento como sofrimento próprio (2003a, 110-1).

\section{Como defendemos, portanto, a crítica nietzscheana ao conhecimento no período de $\mathrm{O}$ Nascimento de tragédia pode ser entendida a partir do pressuposto de uma distinção de}

\footnotetext{
${ }^{14}$ Embora fuja às pretensões deste artigo, poderíamos aqui nos interrogar sobre a continuidade, no pensamento nietzscheano da maturidade, disto que estivemos a chamar de distinção gnosiológica, bem como pela consequente relevância desta para a sua filosofia. Tomaríamos aqui como argumento a tese bastante aceita entre intérpretes e comentadores, de uma "ruptura" no programa filosófico de Nietzsche - ruptura que teria como ponto de inflexão a publicação de Humano, demasiado humano em 1878 e que refletiria a crise pessoal que o acompanhara desde 1876, não só pelo agravamento de seu estado de saúde como pela cisão com relação ao projeto artístico de Wagner e à filosofia de Schopenhauer. Especificamente com relação a seu educador, mesmo a defesa da tese oposta, da existência de uma "continuidade crítica" entre os dois períodos - a partir dos fragmentos e cartas anteriores à publicação de O Nascimento da tragédia, bem como dos trechos suprimidos de sua versão original - em nada deporia a nosso favor.Fazemos aqui referência ao fragmento 12[1] de 1871 (NIETZSCHE KSA-VII, 359), preparativo para a publicação de O Nascimento da tragédia, anteriormente mencionado (cf. nota 9 acima). Embora concordemos que a metafísica de artista e o seu propósito formativo já não fazem parte do programa filosófico nietzscheano no período que se inicia com Humano, demasiado humano, a nosso ver, parece ser possivel apontar sinais daquilo que estivemos a chamar de distinção gnosiológicaentreconhecimento e compreensão- embora talvez não mais como oposição - na maturidade de seu pensamento. Mesmo nesse período, é possível perceber a constante referência e apreço à "simplicidade" e "superficialidade" gregas: "Oh, esses gregos! Eles entendiam do viver! [...] eram superficiais - por profundidade (2004b, 14-15). Ou ainda, de modo mais implícito, àHeiterkeit grega - agora, na "linguagem" do "homem do conhecimento" Nietzsche, como gaia ciência $(1998,14)$. Tal qual o "conhecimento trágico" de seus escritos de juventude, que "restaura os direitos da arte", a gaia ciência, ao fazer-se boa vontade de profundidade, reconhecendo-se a si própria como criadora, reconhece também o valor da superfície: da arte como "boa vontade de aparência" - força contrária sem a qual a percepção da "grande dor seria intolerável". Ciência e arte: "retidão" e "culto do não-verdadeiro". Embora essa tensão não seja mais vivida na forma de uma tragicidade, mas da superficialidade e da "dança", é aqui - arriscamos - que a distinção entre conhecimento e compreensão pode ser percebida: não mais como oposição, mas como limite. Ou antes, como consciência da aparência (2004b, 92). Problematizar tal distinção no pensamento de maturidade de Nietzsche, como dissemos, requereria maior fôlego, o que foge aos propósitos desse artigo. Esta breve especulação, no entanto, sugere realizá-la em outra oportunidade.
} 
cunho gnosiológico mais amplo - remontando à distinção

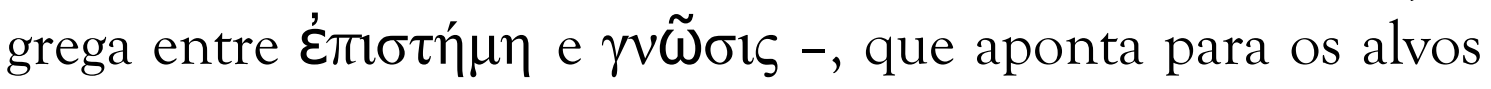
"supremos" distintos, ciência e sabedoria, a partir de duas vias também distintas: do conhecimento (Erkenntni $\beta$ ) e da compreensão (Verständnis), sendo esta última a via a ser trilhada por uma filosofia e uma cultura que se propõem trágicas.

Abstract: Since a reading of young Nietzsche's criticism of the desire of knowledge that guides modernity - particularly regarding to the distinctions he operated between: a) two postures facing reality: the theoretical optimism and the tragic pessimism; and b) two types of man: the theoretical and the artist ones;and c) two kinds of philosophy and philosophers: the one of the desperate knowledge and the other, of the tragic knowledge - we aim to defend, as an access-key to nietzschean's thought from the period of The Birth of Tragedy, the presence of a larger, gnosiological distinction between two forms of access to real: via knowledge (Erkenntniß) and via understanding (Verständnis) $\dot{\varepsilon} \pi \mathbf{T} \sigma \eta \hat{\mu} \mu \eta$ (epistéme) and $\gamma v \tilde{\omega} \sigma ı \zeta$ (gnôsis) -, leading respectively to the targets of science and wisdom.

Keywords: science; understanding; knowledge; wisdom.

\section{REFERÊNCIAS}

ALMEIDA, C. L. S. de; OLIVEIRA, M. A. de (orgs.). Metafísica contemporânea. Petrópolis: Vozes, pp.13-45, 2007.

ARALDI, Clademir. Niilismo, criação, aniquilamento. São Paulo: Unijuí, 2004.

CAVALCANTI, Anna H. Símbolo e alegoria: a gênese da concepção de linguagem em Nietzsche. 2003. 250f. Tese (Doutorado em Filosofia). Universidade Estadual de Campinas, Campinas. 2004.

- Fragmento 12(1): a crítica do jovem Nietzsche à metafísica da vontade de Schopenhauer. Disponível em: http://www.hypernietzsche.org/static/ahartmanncavalcanti 


\section{$-1 / 1 / .2004$.}

GIACÓIA Jr., Oswaldo. Fim da metafísica e os pósmodernos.In: IMAGUIRE, G.; Metafísica contemporânea, pp.13-45, 2007.

LANGE, Friedrich Albert. História do materialismo. Trad. Lôbo Vilela. Lisboa: Gleba, [195-]. 2 v.

LOPES, Rogério A. Ceticismo e vida contemplativa em $\mathrm{Ni}$ etzsche. 2008. 573f. Tese (Doutorado em Filosofia). Universidade Federal de Minas Gerais, Belo Horizonte, 2008

NIETZSCHE, Friedrich W. Sämtliche Werke: Kritische Studienausgabe (KSA). Orgs. G. Colli e M. Montinari. Berlim; Munique; Nova York: Walter de Gruyter / DTV, 1999. $15 \mathrm{v}$.

. Gesammelte Werke. Munique: Musarion, [1922?]. Vol.1: Jugendschriften 1858-1868. (Scan).

.A Arte em O Nascimento da Tragédia-1888 (ANT). In: Nietzsche - Obras Incompletas. Trad. Rubens R. Torres Filho. Sel. Gerard Lebrun. 4⿳亠丷⿵冂丶 ed. São Paulo: Nova Cultural, 1987a. Coleção Os Pensadores vol.1.

- Ecce Homo (EH). Trad. Paulo César de Souza. $2^{a}$ ed. São Paulo: Companhia das Letras, 2004a.

. Filosofia na Época Trágica dos Gregos (FTG). In:

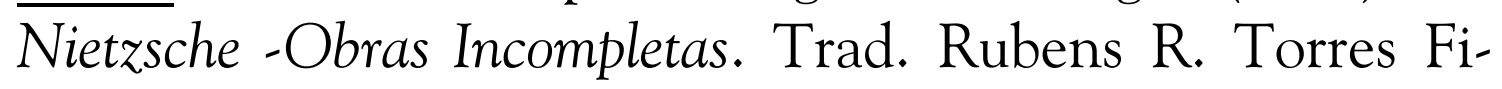
1ho. Sel. Gerard Lebrun. 4⿳a .ed. São Paulo: Nova Cultural, 1987b. Coleção Os Pensadores vol.2.

- A Gaia ciência (GC). Trad. Paulo César de Souza. 
São Paulo: Companhia das Letras, 2004b.

- Genealogia da moral. Trad. Paulo César de Souza. São Paulo: Companhia das Letras, 1998.

. Música e Palavra. In: Revista Discurso. Trad. Oswaldo Giacóia Jr. São Paulo: Alameda, 2007, p. 167 a 181.

- O Nascimento da Tragédia (GT/NT). Trad. Jacó Guinsburg. São Paulo: Companhia das Letras, 2003a.

. Kritische Sämtliche Briefe (KSB-II, pp. 159-160), Edição em oito volumes das cartas de Nietzsche organizada por G. Colli e M. Montinari.Tradução de Rogério A. Lopes. Apud. LOPES, Rogério A. Op. cit. p.86-7.

- Segunda consideração intempestiva: da utilidade e desvantagem da história para a vida (UB/CEx-II). Trad. de Marco Antônio Casanova. Rio de Janeiro: Relume Dumará, 2003b.

- A Visão Dionisíaca do Mundo (DW/VD). Trad. Marcos Sinésio P. Fernandes; Maria Cristina dos S. de Souza. São Paulo: Martins Fontes, 2005.

RODRIGUES Jr., Ruy de Carvalho. Schopenhauer: uma filosofia do limite. 2011. 305f. Tese (Doutorado em Filosofia). Pontifícia Universidade Católica, São Paulo. 2011. 